
\title{
28 Research Suare \\ Legitimacy and procedural justice: how might stratospheric aerosol injection function in the public interest?
}

Marco Grasso ( $\square$ marco.grasso@unimib.it )

University of Milan-Bicocca Faculty of Sociology: Universita degli Studi di Milano-Bicocca Dipartimento di Sociologia e Ricerca Sociale https://orcid.org/0000-0002-6869-5959

\section{Research Article}

Keywords: Stratospheric aerosol injection, Legitimacy, Procedural justice, Criteria, Standards, Public interest

Posted Date: June 3rd, 2021

DOI: https://doi.org/10.21203/rs.3.rs-529885/v1

License: (a) (1) This work is licensed under a Creative Commons Attribution 4.0 International License. Read Full License 


\section{Abstract}

The success of stratospheric aerosol injection (SAI) in limiting global heating requires the inclusion and maintenance of the political ideals of legitimacy and procedural justice. Without them, the prospects are slim that this institution can be developed and operated in the public interest in such a way that it will protect and promote social well-being by minimising climate-related harm.

Long term legitimacy and procedural justice are crucial to several sensitive features of SAl. They relate to openness, inclusivity and independence, in dealing both with external issues of concern to stakeholders representing the general public and with internal issues concerning agents directly involved in SAI.

This article begins by outlining notions of legitimacy and procedural justice, and the criteria appropriate for SAl. Then it investigates how the moral indications provided by the related standards might ensure that SAl is not distorted in such ways that it serves the selfish interests of private parties. Finally, the article outlines two governance recommendations for ensuring that legitimacy and procedural justice in SAl are achieved and maintained over time, so that it can work continuously in the public interest.

\section{Introduction}

Solar geoengineering (SG) aims to reduce the amount of solar energy reaching the Earth in order to reduce regional or global temperatures (Caldeira et al., 2013). The article's arguments refer exclusively to stratospheric aerosol injection (SAI), perhaps the most debated SG approach. SAI imitates the cooling effect of a volcanic eruption through the dispersion of inorganic particles - typically sulphates or calcium carbonate - in the lower stratosphere. The article will focus on this approach for two reasons: SAl's high leverage - its capacity to exert great influence over the climate system from relatively limited technological and economic inputs - and its potential for rapid deployment (Zürn and Schäfer, 2013). These features, and the intrinsic challenges it poses, make an examination of SAl very instructive for a greater overall understanding of SG.

This article illustrates a way to provide SAI with long-term legitimacy and procedural justice, which will enhance its prospects of being developed and carried out in the public interest.

SAl is understood here as an institution for researching and deploying approaches to reducing temperatures by diminishing absorbed solar energy. Drawing on insights from evolutionary economics, neo-institutional theory and economic sociology, this broad notion consists of an institutional complex of coordinated patterns of behaviour. It involves numerous agents, organized through a range of structures, mechanisms, instruments and rules, formal and informal. All of this is determined by a variety of technological inputs, regulations, policies, markets, organisations and networks. An institutional complex of great intricacy, indeed; for the sake of simplicity this article refers to SAl solely as an institution, meaning both the processes involved and the outcomes generated. This brings the advantage that the contentious distinction between SAI research and deployment (Jinnah et al., 2018) can be ignored as irrelevant because, as an institution, SAl includes research, development, experimentation, and gradual 
deployment. In this perspective, SAl is, therefore, the locus of legitimate and procedurally just governance that coordinates the organized behaviours of different agents over different jurisdictions and time periods. In brief, SAI as an institution - and not, for example, any particular SAI research project - is the object of this analysis of legitimacy and procedural justice.

The impending climate crisis (IPCC, 2018; UNEP, 2019) might well make necessary the use of (as yet) uncertain and controversial approaches such as SAI - in addition to other, complementary strategies (Keith, 2013), in particular mitigation and negative emissions technologies (NET) (e.g. MacMartin et al., 2018). At the same time, the inclusion of the political properties - or ideals (Pettit, 2012) - of legitimacy and procedural justice in SAI is crucial for investigating the key features of this institution's policy and governance (SRMGI, 2011; Bodle et al., 2014; Schäfer et al., 2015; Frumhoff and Stephens, 2018; Hourdequin; 2018; Callies, 2019a,b).

Given its complexity and its many unknowns, there is clearly a need for normative analyses of SAI. Numerous works have already examined its normative desiderata, such as effectiveness (e.g. Buck et al., 2020), efficiency (e.g. Moriyama et al., 2017), distributive justice (e.g. Svoboda, 2017), and political feasibility (e.g. Grasso, 2019). Others have explored its legitimacy - as clarified in the following sections - but with different perspectives, notions, and scopes from the ones employed in this article. Nor do more than a few works focus on its procedural justice; one notable exception is Callies (2018; 2019a), but his work regards procedural justice as only one of a series of criteria for judging the legitimacy of SG.

The other main justification for further scrutiny of legitimacy and procedural justice in SG is that these two political properties, given the permeability of this family of approaches to exogenous interferences (Szerszynski et al., 2013; Zürn and Schäfer, 2013), are critical to SG's ability to work in the public interest and generate stable widespread support amongst civil society.

Additionally, SG has become a major focus of legitimation and de-legitimation, with the policy and academic literature divided into two camps. Enthusiasts argue that its effectiveness and efficiency far outweigh any possible illegitimacy and injustice, and sceptics argue that the high levels of risk and the distributional concerns involved mean it should not be countenanced.

This article investigates the notions of legitimacy and procedural justice that SAI should embrace if it is to obtain and maintain the long-term capacity to work in the public interest to limit global heating. After clarifying why legitimacy and procedural justice are critical for SAl, the article outlines appropriate meanings for these political properties, paying particular attention to the sensitive issues of openness, inclusiveness and independence. It goes on to specify the suitable legitimacy and procedural justice criteria and standards, and finally to conclude by outlining two recommendations on governance by which legitimacy and procedural justice can be achieved and maintained over time.

\section{The Importance Of Legitimacy And Procedural Justice In Sai}


SAl is a high leverage institution that could be called into play at relatively short notice. It is, however, hampered by a lack of factual knowledge and fraught by physical, socio-political, and moral issues (Halstead, 2018) that pose not only governance problems (Horton and Reynolds, 2016; Pasztor et al., 2017; Reynolds, 2019) but even fears that it is ungovernable (Talberg et al., 2018).

One major challenge is to avoid SAI being outsourced or captured by elites led by technocrats, bureaucrats, and investors (Szerszynski et al., 2013; Winsberg, 2021), who could manipulate decisionmaking processes in their own interests (Hamilton, 2013). The way to minimise this danger is to ensure that legitimacy and procedural justice are part of SAl, as implied by the conclusions of prior studies (SRMGI, 2011; Morrow et al., 2013; Rayner et al., 2013; Zürn and Schäfer, 2013; Bodle et al., 2014; Schäfer et al., 2015; Frumhoff and Stephens, 2018; Smith, 2018; Callies, 2018, 2019a; Grasso, 2019; Morrow, 2020). They are the most appropriate political properties for ensuring that this institution works in the public interest, as they necessitate, per se, openness, inclusiveness and independence. As other authoritative works emphasise, implicitly or explicitly, (e.g. Bodle et al., 2014; Schäfer et al., 2015; Chhetri et al., 2018; Pasztor et al., 2019), the inclusion of these ideals in SAl will help to reduce the risk that it is exploited by private vested interests taking advantage of dubious governing structures (Zürn and Schäfer, 2013), asymmetries of power and knowledge, deceit, disinformation or other malpractices. Openness, inclusiveness and independence should be sought in SAl's external relationships - where they are a matter of legitimacy - with stakeholders, e.g. decision-makers, social movements, epistemic communities, investors, and experts from techno-scientific groups (Hamilton, 2013). Procedural justice applies to internal issues, concerning which agents that should be involved in SAl and the manner of their participation (Schäfer et al., 2015).

Some scholars (e.g. Bodansky, 2013), however, actively discourage the establishment of new governance systems for SG, citing the potential problematic co-existence of their decision-making authority with the current relevant ones, and their likely burdensomeness. They argue that the legal mandates and the political capabilities required to manage SG appropriately already exist, including joint governance structures, preferably under the aegis of the United Nations. Others, conversely, suggest that new governance systems are needed for the rapid development of SG research. With regard to the argument of this article, these latter scholars outline general frameworks or proposals for shaping sub-state (e.g. Jinnah et al., 2018), international (e.g., Horton et al., 2018) or polycentric and spontaneous systems (e.g. Nicholson et al., 2018; Talberg et al., 2018), as well as global deliberative bodies to lend SG legitimacy and/or authority (e.g. Morrow, et al., 2013; Parson, 2017; Jinnah et al., 2019).

This article does not enter the controversy, but argues that legitimacy and procedural justice should be endogenous to SAl, rather than granted, or not, by onerous external governance systems. The parsimony allowed by this novel locus of legitimacy and procedural justice affords us the opportunity to explore how SAl's feasibility, and its ability to work in the public interest, can be enhanced.

We need to clarify our use of public interest, of which, despite the pervasiveness and influence of the term, there is no generally agreed definition. In democratic societies, it is usually perceived as allowing 
public action to be judged, and to serve as its guide and scrutiniser (Downs, 1962). Accordingly, this article will use public interest to mean the yardstick to measure whether, and to what extent, public actions benefit society as a whole, rather than just specific groups (Steffek, 2015). In particular, with regard to the current climate crisis, public interest relates to SAl's long-term objective of protecting and promoting social well-being through the minimisation of climate-related harm.

\section{Background Issues And The Criteria Of Legitimacy And Procedural Justice In Sai}

Both legitimacy and procedural justice offer normative justification to institutions. They are closely intertwined, but they focus on different elements (Rawls, 2005, 427-429; Buchanan and Keohane, 2006; Buchanan, 2010): legitimacy concerns the institution itself, whereas procedural justice relates to how its decisions are made (Page, 2012). Thus, it is useful to separate the analyses of legitimacy and procedural justice.

To articulate legitimacy and procedural justice in such a way as to make them achievable in the long term, it is worthwhile defining the nature and objectives of criteria and standards with regards to SAl.

Criteria, in general, should be understood as the long-term moral yardsticks that SAl should take into consideration, and gauge its actions against. Criteria will, therefore, contribute to its acting consistently with its objectives, avoiding its being used against the interests of the public. They help interpret the moral landscape in which SAI operates, without necessarily mandating any particular direction to be taken.

Standards are moral references that should inform an institution's functioning, consistent with the general context set by criteria. A standard provides more concrete - although not case-specific - moral indications for organising SAI consistently with the related criterion.

It should be noted that the milieux of reference for criteria and standards are mainly of a moral character. On the one hand, legitimacy and procedural justice are eminently moral constructs which aim at increasing the overall morality of SAl; on the other hand, SAI remains morally contentious, and its almost endless moral implications vigorously challenge dominant beliefs and attitudes (Baatz et al., 2016). These two considerations provide the rationale for framing the analysis of criteria and standards in moral terms.

Additionally, it should be pointed out that criteria and standards work at different levels. Criteria are very broad, and so it can be extremely difficult to draw reliable conclusions as to how they can be satisfied. Standards, on the other hand, can be expressed in narrower, more understandable ways, which makes them crucial for assessing the overall legitimacy and procedural justice of SAI. They operate, therefore, as proxies that can either be met or not, determining whether the specified criteria are satisfied: they provide moral indications for SAI to act consistently with the criteria, in the public interest. 
For example, certain subjects might not be able to recognise whether an SAl enterprise is properly managed. But as long as SAl is shaped so as to avoid excessive burdens on more vulnerable people, is transparent, guarantees the fair involvement of relevant agents and ensures access to accurate knowledge about its functioning, it should be possible to determine whether such an SAI enterprise is being operated in a legitimate and procedurally just way and catering to the public interest.

Finally, although the criteria and (to an extent) the standards described below are taken from the general literature on legitimacy and procedural justice, they are specifically shaped and developed to maximise the extent to which SAl functions in the public interest. Indeed, as we repeatedly emphasise, there is a significant risk that this institution will be captured by elites and forced to work in favour of private/vested interests. The criteria and standards that SAI should pursue are meant to involve different yet complementary constituencies, given the diverse normative scope of legitimacy and procedural justice: the former focuses on how institutions should connect externally and the latter on how they should operate internally.

The criteria and standards of legitimacy relate to external issues concerning its openness, inclusivity and independence and address a broad number of stakeholders representative of the general public, e.g. decision-makers, social movements, professional networks, investors, and experts from techno-scientific groups. Those of procedural justice concern internal issues and are targeted at fewer agents: those directly involved in SAI and the manner of their participation. This inclusiveness provides further reason to believe that the criteria and standard developed will maximize the likelihood of SAI working in the public interest.

This section scrutinises criteria of legitimacy and procedural justice and the following one deals with the analysis of the related standards.

\subsection{Criteria of Legitimacy}

The general reference is to normative legitimacy, as it offers a benchmark of the acceptability or justification of institutions. The notion that is required of normative legitimacy, it should be noted, applies to all types of institutions, regardless of power, authority and coercion, which are the cornerstones of the usual right to rule understanding (Buchanan, 2013), which traditionally refers to states. This notion should also take into account the purpose of the institution to which it is applied (Adams, 2020): SAl may not wield any power or authority, nor apply coercion, and its legitimacy may, for example, concern the systematic coordination of different stakeholders over different jurisdictions.

This article argues for a view of normative legitimacy quite different from the descriptive one commonly used by other studies on SG (e.g. Frumhoff and Stephens, 2018; Jinnah et al., 2018), which maintain that determinants of legitimacy cannot be established a priori from a checklist (Bernstein, 2011, p. 42), that is to say, normatively. Rather they can only be developed positively, based on the acceptance of those involved. Here, though, we argue that normative legitimacy is indispensable for institutions to gain moralbased support - not only strategic or self-interested (Buchanan and Keohane, 2006) or coercion-based 
backing (Hurrell, 2005; Buchanan, 2013) - and specifically to foster an open, inclusive, and independent SAI. It is also true that, given the obvious interdependence of the two notions of legitimacy (Clark, 2005), if an institution is normatively legitimate, it would also see its descriptive (or sociological) legitimacy simultaneously enhanced (Buchanan and Keohane, 2006, p. 436).

The distinctive features of SAl, such as its multifariousness and compositeness, its current state of inexistence and unknowability, its general non-coercive role, its scalability and its capturability, make it difficult to nominate a suitable notion of normative legitimacy from among those already developed. An appropriate one seems to be that of output legitimacy as framed and analysed by Steffek (2015), based on Fritz Scharpf's seminal works on input and output legitimacy (Scharpf, 1970, 1999). It concerns the design of institutions whose output serves the public interest by benefitting people and safeguarding their rights. This emphasis on serving the public interest is also stressed by Zürn and Stephen (2010, p. 94), who argue that any "... justification [of legitimacy] is an appeal to the common interest of the collective."

Although universal criteria for the legitimacy of institutions do not exist it is possible to determine suitable ones by drawing on the relevant literature (Buchanan and Keohane, 2006; Zürn and Stephen, 2010; Keohane, 2011; Buchanan, 2013, and to make specific reference to SG legitimacy Morrow et al., 2013; Callies 2018, 2019a). Given its functional nature, SAI should abide by two criteria that specifically refer to external issues, i.e. to the relationship of this institution with stakeholders representative of the general public. The first requires that SAl avoid inflicting serious injustices; the second compels SAl to provide sound information for dealing with normative disagreement and uncertainty (Buchanan and Keohane, 2006).

If the SAl's choices were to cause serious injustice, it would be falling short of its mandate to protect the public interest by promoting social well-being. Similarly, if it failed to produce and share reliable information continuously, it would become opaque, which would also hinder the pursuit of the public interest by making it easier for unaccountable elites to manipulate its operations in their interests.

For the sake of simplicity, we will refer to this normative notion of output legitimacy simply as legitimacy. The two criteria of legitimacy appropriate for SAl introduced above are:

- avoidance of serious injustice,

- provision of reliable information.

With regard to the avoidance of serious injustice criterion the SAl's first duty is to prioritise more vulnerable people. There is ample evidence of the potential consequences of SAI on the more vulnerable and of the importance of the involvement of stakeholders who represent them in SAl decisional processes. Their early engagement is essential to ensuring that humanitarian considerations taking into account the particular needs, priorities, and opportunities of the more vulnerable are integrated into this institution (Suarez and van Aalst, 2017), especially given the existence of predatory behaviour by elites. In this context it is useful to refer to a starting point notion of vulnerability, also termed social vulnerability (Kelly and Adger, 2000). In a broader perspective, the ethical imperative to put the most vulnerable first is 
very widely accepted, including in relation to the climate crisis where particular concern is felt for weaker and more socially vulnerable agents (Grasso and Markowitz, 2015). Furthermore, more socially vulnerable people are more likely to be exposed to the possible harm - unknown in magnitude and distribution, but potentially significant - associated with SAl; universal principles of justice state, however, that all people - and, indeed, the more vulnerable - have a moral right not to suffer harm (Shue, 2015).

The criterion of provision of reliable information refers to SAl's need to maintain public trust in the long term, which is not easy, given the complexity and uncertainty of this institution. Channels need to be established for transmitting reliable information to stakeholders in order to avoid disagreement and/or facilitate reconciliation (Winsberg, 2021). As well as the risk of appropriation, its mode of operation might become quasi-autocratic, behind closed and impenetrable doors, hidden from the gaze of society and stakeholders. This, indeed, has happened within other climate institutions, for instance - to some degree - with the flexibility mechanisms of the Kyoto Protocol (Sabel and Victor, 2017). So, in order to combat these risks and to dampen the threat that SAI serves vested interests - and indeed to magnify its ability to work in the public interest despite external interference - its institutional complex needs to produce accurate information, despite the fact that the only undeniable trait of this institution, in current circumstances, is uncertainty. Dealing with uncertainty requires multiple strata of information, particularly relevant in several areas, so those stakeholders who are or may be affected by a decision should have the opportunity to contribute, based on their competence and ability, to the relevant operations and processes of SAl.

\subsection{Criteria of procedural justice}

Before analysing procedural justice, a specification is necessary. The normative goal of this political property may seem very similar to that of input legitimacy referred to above, since both relate to involvement in decisional processes. But with regard to SAl, the focus of input legitimacy would not be particularly relevant for this institution to work in the public interest. This is because input legitimacy focuses on an institution's arrangements allowing stakeholders to communicate their interests to the institution's decision-makers and therefore largely concerns external issues. Procedural justice, on the other hand, is relevant because it is pertinent to internal issues regarding the normative qualities of the institution's decision-making: procedural justice covers a space of non-distributive normative problems, thereby differing from input legitimacy. This internal space relates to the agents who interact with an institution, whereas legitimacy concerns the arrangements through which an institution connects externally with stakeholders. Consequently, procedural justice imposes criteria and standards to SAI whose scope is different from the one legitimacy entails.

Procedural justice operates, however, in synergy with the notion of legitimacy employed to grant the openness, inclusiveness and independence necessary for SAI to work in the public interest. This section investigates procedural justice in order to develop criteria suitable for SAl. 
Procedural justice deals with how relations between SAI and agents involved in it are managed and how the correct functioning of the rules of the game of such relations is safeguarded. The most important procedural rules of the game - to ensure openness, inclusiveness, and independence - refer to the participation and recognition of the relevant agents (Barry, 2002), specifically to their fair involvement in SAl and to their understanding of the issues at stake.

The current analysis of procedural justice, echoing the earlier investigation of legitimacy, aims to understand which components of procedural justice SAI should include in order to maximise its ability to work in the public interest. This section, therefore, defines the most suitable criteria and the next section, based on these criteria, will outline the moral indications that the related standards can provide.

Drawing on Barry (2002, pp. 97-99), SAl procedural justice can be grounded in two fundamental criteria:

- impartiality. the involvement in SAI of the relevant agents, all of whom having parity of participation (Fraser, 2005);

- equality of opportunity. all agents must have the same opportunity to fully understand the issues at stake in SAI (Page, 2012).

The impartiality criterion means that SAI should ensure the involvement of the relevant agents on an equal footing: SAI can attain procedural justice when the same rules, procedures, and formalities are applied to all agents. In particular, SAI should incorporate agreed arrangements for how agents are selected for inclusion, for how they interact with each other on internal issues and for how they connect with non-internal issues. The rules for agents should be non-arbitrary and non-biased. It is also necessary for the relevant agents to control the functioning of such arrangements. Additionally, all SAl initiatives should maximise the cultural and social diversity of all agents involved.

The equality of opportunity criterion relates in different ways to knowledge and is fundamental to reducing the complexity of SAI - one of its salient traits. Equality of opportunity means that all the relevant agents' concerns must be considered, such that potential conflicts are minimised between the institution itself and agents, and amongst agents, and that interactions between agents are seen as fair. Equality of opportunity is achieved when all agents play a proportionately equal role in SAI.

\section{Standards Of Legitimacy And Procedural Justice In Sai}

The current section outlines the moral implications for SAI of the standards of legitimacy and procedural justice. Standards should be understood as ordinal principles that are designed to work synergistically, i.e. the better SAI satisfies all of them at the same time, the more the public can be confident that SAI is operating in the public interest. Standards need both to capture the complexity of criteria and to be epistemically accessible (Buchanan, 2013, p. 193), that is comprehensible by the largest possible number of agents, stakeholders, and outside individuals. This is not an easy combination, and striking a balance between these two contrasting requirements 
might seem to be an intractable challenge. As emphasised above, standards should be wholly and continuously contextualised - that is with specific reference to the particular SAI enterprise - and the nature of the structure required is indicated in the next section. This section simply delineates the general moral indications that standards provide to SAI.

The following table gives an overview of the criteria and standards of legitimacy in SAI. It is worth recalling that although their labels are familiar, the originality of the proposed criteria and standards lies in their contents, scope, and objectives, as specified above.

Table 1 - Criteria and standards of legitimacy and procedural justice

\begin{tabular}{|l|l|l|}
\hline & Criterion & Standard \\
\hline \multirow{2}{*}{ Legitimacy } & Avoidance of serious injustice & Priority \\
\cline { 2 - 3 } & Provision of reliable information & Transparency \\
\hline Procedural Justice & Impartiality & Involvement \\
\cline { 2 - 3 } & Equality of opportunity & Knowledge \\
\hline
\end{tabular}

\subsection{Standards of legitimacy}

I) Avoidance of serious injustice context: Priority standard

The criterion of legitimacy avoidance of serious injustice compels SAI to prioritise the needs of the more vulnerable. Accordingly, the related standard of priority (to the more vulnerable) should abide by a moral principle that prevents SAI from imposing burdens on the more vulnerable that are greater than those suffered by the less vulnerable, and by no means should they exceed those already inflicted by the climate crisis. Additionally, the priority standard demands that SAI provides these vulnerable people with greater benefits than those enjoyed by those less vulnerable, now or in the future global heating scenario. This standard is in line with core moral requirements for more just social arrangements since it shifts the onus from those who bear a greater burden than fairness would require of them - i.e. the more vulnerable ones - to those who shoulder lighter burdens, that is to say, wealthier agents.

II) Provision of reliable information context: Transparency standard

For SAI to achieve the overall trustworthiness required by the legitimacy criterion provision of reliable information, it must be sufficiently transparent in its dealings that stakeholders can monitor its functioning 
effectively. Transparency would also allow SAI to promote accountability (Hale, 2008). To this end, three aspects of transparency are important. First, accurate information must be made available (regularly, not merely upon direct request) to all relevant stakeholders at a reasonable cost; second, information must be accessible to all stakeholders (i.e., in readily usable forms) so that they can act on it; third, stakeholders who use this information should be able to hold the institution accountable (Buchanan and Keohane, 2006, p. 427). Therefore, the minimum required is that SAI should provide the appropriate types and amounts of information to all stakeholders on its goals, procedures and performance. Additionally, this information should be conveyed to stakeholders in ways that make it possible for them to criticise and propose changes to said goals, procedures and performance.

\subsection{Standards of procedural justice}

III) Impartiality context: Involvement standard

On procedural justice, the impartiality criterion demands that SAI involves all the relevant agents. The involvement standard demands that the procedural justice of this institution is monitored and controlled. To satisfy this standard, SAI should promote unbiased decision-making, ensure the consistency of its norms, procedures, processes, structures and instruments across agents and over time and build in the mechanisms needed to ensure that all decisions are modifiable and reversible. This standard should also safeguard the fundamental moral, cultural and social values of agents (Grasso and Sacchi, 2015). In brief, to comply with the involvement standard, SAI should be proactive in engaging agents to monitor and scrutinise its overall functioning.

IV) Equality of opportunity context: Knowledge standard

The equality of opportunity criterion requires that the agents involved in an institution be equal - or close to equal - in terms of the opportunities they have to understand the functioning of the institution. To achieve this condition, SAI should provide access to accurate and authenticated knowledge, and/or develop its own, despite the inevitable current uncertainties. Given accurate knowledge, decision-making can be based on evidence rather than guesswork or personal bias, and it can thus maximise the benefit to be gained from the knowledge and competence of agents (Dolan et al., 2007). The knowledge standard aims to promote the active participation of agents in all SAI decisional processes through the generation, integration and provision of timely and fit-forpurpose knowledge which reduces its complexity, even in the situation of profound unpredictability that this institution operates in.

Page $11 / 19$ 


\section{Specifications And Recommendations}

The criteria and standards of legitimacy and procedural justice developed are not, however, definitive: horizontally, they may be more, or less, effective in some SAl initiatives than in others and longitudinally they may struggle over time to keep pace with the evolving contexts in which they operate. Additionally, standards can provide only general moral indications: their operational details depend on the individual SAl enterprise and its ever-changing context, and they need to be continuously defined and redefined in socially agreed ways.

These considerations prompt two critical governance recommendations to increase the likelihood of SAI working in the public interest over time. First, legitimacy and procedural justice within SAI must be continuously checked and recalibrated; second, appropriate ways of continuously contextualising and operationalising standards should be established.

\subsection{Check and calibration}

Because SAl is as yet untried and untested, the inclusion of legitimacy and procedural justice requires some innovative thinking and original design work. Ingenuity, however - although often effective in uncertain situations - risks delivering solutions that are not uniformly applicable to all SAI enterprises, failing to keep up with evolving circumstances and losing the focus on the public interest.

Therefore, the criteria and standards outlined above might not always increase the overall legitimacy and procedural justice of SAl, or be able to work beyond the short term. Therefore, a checking process will be vital, one which relies on the knowledge-generating potential of the criteria and standards themselves. The application of the reliable information criterion and the related transparency standard, and the equality of opportunity criterion and the knowledge standard, will enable SAI to carry out the most thorough possible critical review of its legitimacy and procedural justice and of its continuous ability to aim at the public interest.

But contexts change - SAl operates in a dramatically fast-evolving climatic, scientific, technological, economic, and socio-political landscape - and so, potentially, the criteria and standards of legitimacy and procedural justice could become inadequate. To obviate this risk, they should undergo a dynamic process of iterative learning, supporting an iterative, integrated-learning mode of adaptive governance. SAl should, by highlighting and appraising the degree of its consistency with the provisions of legitimacy and procedural justice, be able to calibrate and rearrange standards and criteria to uphold these two ideals over time. In brief, SAl's legitimacy and procedural justice should be addressed in a social-learning mode, dynamically and reflectively (Grasso and Tàbara, 2019). This iterative process would also make SAl more consistent with the requirements of a responsible research and innovation approach. Its institutional complex would be able to engage and re-engage in multiple ways over long periods of time with agents, stakeholders and civil society in order to align its conduct and outcomes with their values and objectives (Low and Buck, 2020) and hence to truly work in the public interest. 


\subsection{Continuous operationalisation of standards}

In order to ensure that the details of standards of legitimacy and procedural justice can be socially agreed upon for the specific SAl enterprise and modified when the contextual changes require it, the establishment of a permanent and independent consultative forum in each enterprise will be beneficial. It would make the necessary decisions - taking into account the outcomes of the checking and calibration process described above - about the contextualised operationalisation and modification of standards. The forum is not a new suggestion in the relevant literature: various authors have proposed such decision making governance structures (e.g. Chhetri et al., 2018; Nicholson et al., 2018; Reynolds, 2019). It is worth stressing here, however, that two distinctive features are needed if the forum is to have the independence necessary to shape, and maintain over time, the required standards of legitimacy and procedural justice.

First, the forum should be external to any SAI initiative, i.e. its members should have no stake in it. Only thus would the forum be both effective and credible and avoid accusations that SAI does not work in the public interest. Second, the make-up of the SAI consultative forum should be inclusive and diverse. It should involve three groups of members - experts, practitioners and representatives from civil society with a balance of gender and global South and the North. Experts should have scientific and/or technological knowledge about SAI and be selected internationally from both the physical and the social sciences communities working on SAI and its governance. The complexity of SAI makes it unfeasible to involve lay people effectively; therefore the second group should consist of practitioners from NGOs working on climate engineering, including those concerned with the most-hard hit developing world. Examples would be the Solar Radiation Management Governance Initiative (SRMGI), the Carnegie Climate Governance Initiative (C2G), The World Academy of Sciences and the Environmental Defense Fund. The third group should include those parts of the global civil society which, despite not being involved in the SAl enterprise, are concerned by it as a wide-ranging socio-political and economic phenomenon: political representatives, social movements, networks of knowledge-based experts, and economic and financial circles.

\section{Conclusions}

This article puts forward a way to provide SAI with the long-term legitimacy and procedural justice it needs if it is to increase its capacity to operate in the public interest. To this end, the article first develops suitable criteria of legitimacy and procedural justice; it then goes on to investigate the moral indications provided by the related standards - epistemically accessible proxies of criteria; finally, it outlines two governance recommendations that will help ensure the achievement and maintenance of the legitimate and procedurally just functioning of SAI in the public interest.

It seems finally worth underlining that the establishment of legitimate and procedurally just SAI would both make it more effective as an institution and able to work in the public interest than could be achieved by any form of imposition, however great our trust in the vision of politicians, or in the exemplary power of scientific evidence. In the current fragmented and multipolar international climate 
order, all climate action needs to operate in a polycentric, quasi-anarchic system, through careful, gradual design and re-design of the relevant institutions. This especially applies to SAl, as it significantly interferes with vested interests, influences patterns of well-being across states, peoples, and generations, and modifies the flow of huge amounts of resources, not least financial ones. The inclusion and maintenance of legitimacy and procedural justice in SAI would shape converging preferences among agents, stakeholders and political representatives in support of this institution, even those coming from differing political traditions and subject to different political constraints. Ultimately, therefore, the likelihood that SAI would work in the best interests of the public would be significantly enhanced.

\section{References}

Adams, N. P. (2020). Legitimacy and institutional purposes. Critical Review of International Social and Political Philosophy, 23 (3), pp. 292-310. https://doi.org/10.1080/13698230.2019.1565712

Baatz, C., Heyward, C. and Stelzer H. (2016). The ethics of engineering the climate. Environmental Values, 25 (1), pp. 1-5. https://doi.org/10.3197/096327115X14497392134766

Barry, B. (2002). Political Argument: A Reissue with a New Introduction. Berkeley, Ca.: University of California Press.

Bernstein, S. (2011). Legitimacy in intergovernmental and non-state global governance. Review of International Political Economy, 18 (1), pp. 17-51. https://doi.org/10.1080/09692290903173087

Bodansky, D. (2013). The who, what, and wherefore of geoengineering governance. Climatic Change, 121 (3), pp. 539-551. https://doi.org/10.1007/s10584-013-0759-7

Bodle, R. et al. (2014). Options and Proposals for the International Governance of Geoengineering. Berlin: Ecologic Institute [online]. Available from: https://www.ecologic.eu/11052 [Accessed 13 May 2021].

Buchanan, A. (2010). The legitimacy of international law. in S. Besson and J. Tasioulas (eds.), The Philosophy of International Law. Oxford: Oxford University Press, pp. 79-96.

Buchanan, A. (2013). The Heart of Human Rights. Oxford: Oxford University Press.

Buchanan, A. and Keohane, R. O. (2006). The legitimacy of global governance institutions. Ethics \& International Affairs 20 (4), pp. 405-437. https://doi.org/10.1111/j.1747-7093.2006.00043.x

Buck, H. J. et al. (2020). Evaluating the efficacy and equity of environmental stopgap measures. Nature Sustainability, 3, pp. 499-504. https://doi.org/10.1038/s41893-020-0497-6

Caldeira, K., Govindasamy, B. and Cao, L. (2013). The science of geoengineering. Annual Review of Earth and Planetary Sciences, 41. https://doi.org/10.1146/annurev-earth-042711-105548 
Callies, D. E. (2018). Institutional legitimacy and geoengineering governance. Ethics, Policy \& Environment, 21(3), pp. 324-340. https://doi.org/10.1080/21550085.2018.1562523

Callies, D. E. (2019a). Climate Engineering: A Normative Perspective. Lanham, MD: Lexington Books.

Callies, D. E. (2019b). The slippery slope argument against geoengineering research. Journal of Applied Philosophy, 36(4), pp. 675-687. https://doi.org/10.1111/japp.12345

Chhetri, N.; Chong, D.; Conca, K.; Falk, R.; Gillespie, A.; Gupta, A.; Jinnah, S.; Kashwan, P.; Lahsen, M.; Light, A.; et al. (2018). Governing Solar Radiation Management. Washington, DC: Forum for Climate Engineering Assessment, American University [online]- Available from: https://doi.org/10.17606/M6SM17. [Accessed 13 May 2021].

Clark, I. (2005). Legitimacy in International Society. New York, NY: Oxford University Press.

Dolan, P., Edlin, R., Tsuchiya, A. and Wailoo, A. (2007). It ain't what you do, it's the way that you do it: characteristics of procedural justice and their importance in social decision-making. Journal of Economic Behavior \& Organization, 64 (1), pp. 157-170. https://doi.org/10.1016/j.jebo.2006.07.004

Downs, A. (1962). The public interest: Its meaning in a democracy. Social Research, 29 (1), pp. 1-36.

Fraser, N. (2005). Reframing justice in a globalizing world. New Left Review, 36, pp. 69-88.

Frumhoff, P. C. and Stephens, J. C. (2018). Towards legitimacy of the solar geoengineering research enterprise. Phil. Trans. R. Soc. A, 376, 20160459. https://doi.org/10.1098/rsta.2016.0459

Grasso, M. (2019). Sulfur in the sky with diamonds: An inquiry into the feasibility of solar geoengineering. Global Policy, 10 (2), pp. 217-226. https://doi.org/10.1111/1758-5899.12646

Grasso M. and Sacchi S. (2015). Impure procedural justice in climate governance systems. Environmental Values 24 (6), pp. 777-798. https://doi.org/10.3197/096327115X14420732702699

Grasso, M. and Tàbara J. D. (2019). Towards a moral compass to guide sustainability transformations in a High-End Climate Change world. Sustainability, 11 (10), 2971.

Hale, T. N. (2008). Transparency, Accountability and Global Governance. Global Governance, 14 (1), pp. 73-94.

Halstead, J. (2018). Stratospheric aerosol injection research and existential risk. Futures, 102, pp. 63-77. https://doi.org/10.1016/j.futures.2018.03.004

Hamilton, C. (2013). No, we should not just 'at least do the research. Nature, 436 (7444), p. 139. https://doi.org/doi:10.1038/496139a 
Horton, J. B. and Reynolds, J. L. (2016). The International politics of climate engineering: A review and prospectus for international relations. International Studies Review, 18 (3), pp. 438-461.

https://doi.org/10.1093/isr/viv013

Horton, J. B., Reynolds, J. L., Buck, H. J., Callies, D., Schäfer, S., Keith, D. W. and Rayner, S. F. (2018). Solar geoengineering and democracy. Global Environmental Politics, 18 (3), pp. 5-24.

https://doi.org/10.1162/glep_a_00466

Hurrell, A. (2005). Legitimacy and the use of force: can the circle be squared?. Review of International Studies, 31(S1), pp. 15-32. https://doi.org/10.1017/S0260210505006765

IPCC (2018) Special Report on Global Warming of $1.5^{\circ} \mathrm{C}$. Geneva: IPCC [online]. Available from: http://www.ipcc.ch/report/sr15/ [Accessed 13 May 2021].

Jinnah, S., Nicholson, S. and Flegal, J. (2018). Toward legitimate governance of solar geoengineering research: A role for sub-state actors. Ethics, Policy \& Environment, 21 (3), pp. 362-381.

https://doi.org/10.1080/21550085.2018.1562526

Jinnah, S., Nicholson, S., Morrow, D. R., Dove, Z., Wapner, P., Valdivia, W., ... and Kashwan, P. (2019). Governing climate engineering: a proposal for immediate governance of solar radiation management. Sustainability, 11 (14), 3954. https://doi.org/10.3390/su11143954

Keith, D. W. (2013). A Case for Climate Engineering. Cambridge, Ma: MIT Press.

Kelly, P.M. and Adger, W.N. (2000). Theory and practice in assessing vulnerability to climate change and facilitating adaptation. Climatic Change, 47, pp. 325-352.

Keohane, R. O. (2011). Global governance and legitimacy. Review of International Political Economy, 18 (1), pp. 99-109. https://doi.org/10.1080/09692290.2011.545222

Low, S. and Buck, H. J. (2020). The practice of responsible research and innovation in "climate engineering”. WIREs Climate Change, 11 (3), e644. https://doi.org/10.1002/wcc.644

MacMartin, D. G., Ricke, K. and Keith, D. W. (2018). Solar geoengineering as part of an overall strategy for meeting the 1.5 C Paris target. Phil. Trans. R. Soc. A, 376, 20160454.

https://doi.org/10.1098/rsta.2016.0454

Moriyama, R. et al. (2017). The cost of stratospheric climate engineering revisited. Mitigation and Adaptation Strategies for Global Change, 22 (8), pp. 1207-1228. https://doi.org/10.1007/s11027-0169723-y

Morrow, D. R. (2020). A mission-driven research program on solar geoengineering could promote justice and legitimacy. Critical Review of International Social and Political Philosophy, 23 (5), pp. 618-640. 
Morrow, D. R., Kopp, R. E. and Oppenheimer, M. (2013). Political legitimacy in decisions about experiments in solar radiation management. in W. C. G. Burns and A. L. Strauss (eds.), Climate Change Geoengineering: Philosophical Perspectives, Legal Issues, and Governance Frameworks. Cambridge: Cambridge University Press, pp. 146-167.

Nicholson, S., Jinnah, S. and Gillespie, A. (2018). Solar radiation management: a proposal for immediate polycentric governance. Climate Policy, 18 (3), pp. 322-334.

https://doi.org/10.1080/14693062.2017.1400944

Page, E. A. (2012). The hidden costs of carbon commodification: Emissions trading, political legitimacy and procedural justice. Democratization, 19 (5), pp. 932-950.

https://doi.org/10.1080/13510347.2012.709689

Parson, E.A., (2017). Starting the Dialogue on Climate Engineering Governance: A World Commission. Waterloo, Ontario: Policy Brief: Fixing Climate Governance Series [online]. Available from: https://www.cigionline.org/publications/starting-dialogue-climate-engineering-governance-worldcommission [Accessed 13 May 2021].

Pasztor, J., Scharf, C. and Schmidt, K-U. (2017). How to govern geoengineering?. Science, 357 (6348), p. 231. https://doi.org/10.1126/science.aan6794

Pasztor et al., (2019). Geoengineering: The Need for Governance. New York: C2G [online]. Available from: https://www.c2g2.net/the-need-for-governance/ [Accessed 13 May 2021].

Pettit, P. (2012). Legitimacy and justice in republican perspective. Current Legal Problems, 65(1), pp. 5982. https://doi.org/10.1093/clp/cus016

Rawls, J. (2005). Political Liberalism: Expanded Edition. New York: Columbia University Press.

Reynolds, J. L. (2019). Solar geoengineering to reduce climate change: a review of governance proposals. Proc. R. Soc. A, 475: 20190255. https://doi.org/10.1098/rspa.2019.0255

Sabel, C.F and Victor, D.G. (2017). Governing global problems under uncertainty: Making bottom-up climate policy work. Climatic Change, 144, pp. 15-27. https://doi.org/10.1007/s10584-015-1507-y

Schäfer, S. et al. (2015). The European Transdisciplinary Assessment of Climate Engineering (EuTRACE): Removing Greenhouse Gases from the Atmosphere and Reflecting Sunlight Away from Earth [online]. Available from: https://www.adelphi.de/en/publication/european-transdisciplinary-assessment-climateengineering-eutrace [Accessed 13 May 2021].

Scharpf, F. W. (1970). Demokratietheorie zwischen Utopie und Anpassung. Konstanz: Universitätsverlag. 
Scharpf, F. W. (1999). Governing in Europe. Effective and Democratic? Oxford: Oxford University Press.

Shue, H. (2015). Historical responsibility, harm prohibition, and preservation requirement: Core practical convergence on climate change. Moral Philosophy and Politics, 2, pp. 7-31.

https://doi.org/10.1515/mopp-2013-0009

Solar Radiation Management Governance Initiative (SRMGI). (2011). Solar Radiation Management: The Governance of Research. [online]. Available from: https://royalsociety.org/topics-policy/projects/solarradiation-governance/report/ [Accessed 13 May 2021].

Steffek, J. (2015). The output legitimacy of international organizations and the global public interest. International Theory, 7 (2), pp. 263-293. https://doi.org/10.1017/S1752971915000044

Suarez, P. and van Aalst, M. K. (2017). Geoengineering: A humanitarian concern. Earth's Future, 5 (2), pp. 183-195. https://doi.org/10.1002/2016EF000464

Svoboda, T. (2017). The Ethics of Climate Engineering: Solar Radiation Management and Non-ideal Justice. New York, NY: Routledge.

Szerszynski, B. K. M., et al. (2013). Why solar radiation management geoengineering and democracy won't mix. Environment and Planning A, 45 (12), pp. 2809-2816. https://doi.org/10.1068/a45649

Talberg, A., Christoff, P., Thomas, S. and Karoly, D. (2018). Geoengineering governance-by-default: an earth system governance perspective. International Environmental Agreements: Politics, Law and Economics, 18 (2), pp. 229-253. https://doi.org/10.1007/s10784-017-9374-9

UNEP (2019). The Emissions Gap Report 2019. Nairobi: UNEP [online]. Available from: https://www.unenvironment.org/resources/emissions-gap-report-2019 [Accessed 13 May 2021].

Winsberg, E. (2021). A modest defense of geoengineering research: A case study in the cost of learning. Philosophy \& Technology. https://doi.org/10.1007/s13347-021-00452-9

Zürn, M. and Schäfer, S. (2013). The paradox of climate engineering. Global Policy, 4 (3), pp. 266-277. https://doi.org/10.1111/gpol.12004

Zürn, M. and Stephen, M. (2010). The view of old and new powers on the legitimacy of international institutions. Politics, 30 (1_suppl), pp. 91-101. https://doi.org/10.1111/j.1467-9256.2010.01388.x

\section{Declarations}

Funding: Not Applicable

Conflicts of interest/Competing interests: Not Applicable Availability of data and material: Not Applicable 
Code availability: Not Applicable

Page 19/19 